\title{
Microencapsulation of Macaranga gigantea Leaf Extracts: Production and Characterization
}

\author{
Muhaimin Muhaimin ${ }^{1,2, *}$, Yusnaidar Yusnaidar ${ }^{1,2}$, Wilda Syahri' ${ }^{1}$, Madyawati Latief ${ }^{2}$, Anis Yohana Chaerunisaa ${ }^{3}$
}

Muhaimin Muhaimin ${ }^{1,2, *}$ Yusnaidar Yusnaidar ${ }^{1,2}$, Wilda Syahri' ${ }^{1}$, Madyawati Latief ${ }^{2}$, Anis Yohana Chaerunisaa ${ }^{3}$

'Department of Chemistry Education, Faculty of Education, University of Jambi, Jambi, 36361, INDONESIA.

${ }^{2}$ Department of Chemistry, Faculty of Science and Technology, University of Jambi, Jambi, 36361, INDONESIA. ${ }^{3}$ Department of Pharmaceutical Technology, Faculty of Pharmacy, Padjadjaran University, Jatinangor, 45363, INDONESIA.

\section{Correspondence}

\section{Muhaimin Muhaimin}

Department of Chemistry Education Faculty of Education; Department of Chemistry, Faculty of Science and

Technology, University of Jambi, Jambi, 36361, INDONESIA.

E-mail: mhn73@yahoo.com

History

- Submission Date: 06-04-2020;

- Review completed: 17-04-2020

- Accepted Date: 27-04-2020.

\section{DOI : 10.5530/pj.2020.12.104}

Article Available online http://www.phcogj.com/v12/i4

\section{Copyright}

(C) 2020 Phcogj.Com. This is an openaccess article distributed under the term of the Creative Commons Attribution 4.0 International license.

\begin{abstract}
Introduction: The aim of this research was to formulate the microcapsules of Macaranga gigantea leaves extract with solvent evaporation method using Ethocel $10 \mathrm{cP}$ and Eudragit E100 as matrix. Methods: M. gigantea leaves were extracted using ethanol $96 \%$. This extract was dried by rotary evaporator. The microencapsulation process of $M$. gigantea leaves extract was conducted by solvent evaporation method (OM: oil in water). The formula of $M$. gigantea leaves extract microcapsules were designed into six formulas (Eudragit E100: FA, FA, FA ${ }_{3}$ and Ethocel $10 \mathrm{cP}: \mathrm{FB}_{1}, \mathrm{FB}_{2}, \mathrm{FB}_{3}$ ). Microcapsules of $\mathrm{M}$. gigantea leaves extract were characterized for particle size, in terms of surface morphology by scanning electron microscope (SEM) and encapsulation efficiency. Antioxidant activity of the formulation have been evaluated by DPPH method. Physical characterization on microparticles were performed by conducting entrapment efficiency and SEM picture. Results: In this research, the micoparticles containing M. gigantea extract has been developed by using ethyl cellulose (Ethocel $10 \mathrm{cP}$ ) and eudragit (Eudragit E100) as polymer matrix. The results showed that high concentration of polymer (Ethocel $10 \mathrm{cP}$ and Eudragit E100) used in microencapsulation resulted in better M. gigantea leaves extract microcapsules in terms of physical characteristics. Particle size of microcapsules containing $M$. gigantea leaves extract were in the range of 3.564 to $5.887 \mu \mathrm{m}$. Encapsulation efficiency (\% EE) was categorized as good because the value were $\geq 80 \%$ to which $85.978 \%$ $\left(\mathrm{FA}_{3}\right)$ and $88.992 \%\left(\mathrm{FB}_{3}\right)$. SEM picture of $\mathrm{FA}_{3}$ (Eudragit E100) revealed that the surface of microcapsule were rough and porous. When Ethocel $10 \mathrm{cP}$ used as polymer, a smoother surface and less visible pores of microcapsule were obtained. The antioxidant ability of $M$. gigantea leaves extract microcapsule showed that $I C_{50}$ values was $64.51 \mathrm{ppm}$. Conclusion: It can be concluded that microcapsules of $M$. gigantea leaves extract can be prepared by solvent evaporation method by using Eudragit E100 and Ethocel $10 \mathrm{cP}$ as polymer matrix. M. gigantea leaves has potent antioxidant activity either as extract or after formulated into microcapsules. Key words: Microencapsulation, Solvent evaporation method, Macaranga gigantea, Eudragit E100, Ethocel $10 \mathrm{cP}$, Antioxidant.
\end{abstract}

\section{INTRODUCTION}

Herbal extracts have been widely accepted as the potential medicines with less side effects as compared to synthetic drug molecules. In recent years, focus has been directed towards the development of drug delivery system using biologically active compounds derived from the natural sources. ${ }^{1,2}$ Herbal-based drug delivery systems have long been used in folk medicine, and herbal medicines of natural origin show good therapeutic activity with minimal side effects. The World Health Organization estimates that $80 \%$ of the world's population currently uses herbal medicines for primary health care. Thus, researchers have begun to focus on herbal drugs and the use of materials of herbal origin. Herbal medicines have many advantages over traditional medicines, including a lower risk of side effects, lower cost, and widespread availability. ${ }^{1-6}$

Medicinal plants are part of the history of human evolution. More than $50 \%$ of all drugs used in modern medicinal treatments are composed of natural products and derivatives thereof. The physicochemical stability is a determining factor in the quality of plant extracts and the transformation of these into dry-powdered form is the most desirable strategy, considering that this form improves its stability and facilitates the manipulation of the material. ${ }^{3,5}$ Techniques for the incorporation of plant extracts within polymer matrices have indicated a good alternative for the improvement of the functionality of medicinal plant extracts. The spraydrying and solvent evaporation process that involves the dispersion of material inside a coated material is a technique that has been widely used in recent years for the incorporation of extracts into polymer matrices. ${ }^{1-6}$

Macaranga is a genus of the family Euphorbiaceae which comprises of about three hundred species. It is present in some parts of the world which include Indonesia, some parts of Africa, Madagascar, Asia, the east coast of Australia and the Pacific islands. ${ }^{7-15}$ The Macaranga gigantea plants are known to be in the form of shrubs or trees and grow in places with optimum sunlight, secondary forests or forests that have been destroyed. Macaranga gigantea plants show several bioactivity which include antitumor, anticancer, antimalaria, antimicrobes,

Cite this article: Muhaimin $M$, Yusnaidar $Y$, Syahri $W$, Latief $M$, Chaerunisaa AY. Microencapsulation of Macaranga gigantea Leaf Extracts: Production and Characterization. Pharmacogn J. 2020;12(4):716-24. 
cyclooxygenase and antioxidant. ${ }^{15-20}$ The plant is also known to have active phytochemicals constituents, especially on its leaves. ${ }^{7,21}$

Solvent evaporation method has been widely and extensively used to prepare polymeric microparticles containing different drugs and in the development of modified release systems..$^{22,23}$ It is a rapid process that does not involve severe heat treatment; therefore, it is a suitable method to preserve biological products, including temperature sensitive products, without their degradation; it also allows for storage at room temperature. It is an instantaneous process where spherical and uniform samples can be obtained, and the process can be easily scaled up. ${ }^{23-26}$ Thermal degradation, nutrient loss, and denaturation are minimal, allowing maximum retention of the active principles. Solvent evaporation method is a technique more economical than lyophilization (four to seven times less costly); it also allows coating, complex coacervation, and drying of two different feed solutions during the process. The effectiveness of the solvent evaporation method to produce microspheres depends on the successful entrapment of the active agent within the particles, and thus, this process is most successful with drugs which are either insoluble or poorly soluble in the aqueous medium which comprises the continuous phase. ${ }^{27-32}$ There are different methods to prepare microparticles by solvent evaporation method. The choice of the method that will give rise to an efficient drug encapsulation depends on the hydrophilicity or the hydrophobicity of drug. ${ }^{33,34}$ The $\mathrm{O} / \mathrm{W}$ emulsion system consists of an organic phase comprised of a volatile solvent with dissolved polymer and the drug to be encapsulated, emulsified in an aqueous phase containing a dissolved surfactant. For insoluble or poorly water-soluble drugs, the oil-in-water $(\mathrm{O} / \mathrm{W})$ method is frequently used. Another alternative to encapsulate hydrophilic drugs is to employ the water-in-oil-in water (W/O/W) emulsion process. An aqueous solution of the drug is added to an organic phase consisting of the polymer and organic solvent with vigorous stirring to form the first $\mathrm{W} / \mathrm{O}$ emulsion. This emulsion is then dispersed in another aqueous phase containing more surfactant to form the $\mathrm{W} / \mathrm{O} / \mathrm{W}$ emulsion. A number of hydrophilic drugs like the peptide leuprolide acetate, a lutenizing hormone-releasing hormone-releasing hormone agonist, vaccines, proteins/peptides and conventional molecules have been successfully encapsulated by this method. ${ }^{23,24,30-35}$

Depending on the polymer used, microencapsulation may control organoleptic modifications and increase the solubility/dissolution rate of the product. A good encapsulating agent (wall material) should have emulsifying and film forming properties, display low hygroscopicity, have low viscosity at high solid contents, resistance to the gastrointestinal tract, be biodegradable, non-toxic, low-cost, bland in flavor/tasteless, soluble in aqueous solvents, and food-grade. ${ }^{23,34,35}$ The study included the development and characterization of the microparticles obtained Macaranga gigantea leaves extract using the solvent evaporation method, and the evaluation of the antioxidant potential of Macaranga gigantea leaves extract from the encapsulated microparticles.

\section{MATERIAL AND METHODS}

\section{Collection of plant materials}

Fresh leaves of M. gigantea were collected in the month of July, 2019 from Mendalo (Jambi) and identified by a taxonomist from the Department of Biology, Faculty of Mathematics and Natural Sciences of Padjadjaran University. The fresh leaves were washed thoroughly to remove dirt and soil, then dried and stored at room temperature. They were grinded and then kept in closed container and stored at room temperature until they will be used for the next process.

\section{Chemicals and reagents}

Quercetin dehydrate, Ethocel $10 \mathrm{cp}$, Eudragit E 100, gallic acid, 1,1-Diphenyl-2-picrylhydrazyl (DPPH), anhydrous sodium carbonate $\left(\mathrm{Na}_{2} \mathrm{CO}_{3}\right)$, aluminum trichloride $\left(\mathrm{AlCl}_{3}\right)$, potassium acetate $\left(\mathrm{CH}_{3} \mathrm{COOK}\right)$, sodium acetate $\left(\mathrm{CH}_{3} \mathrm{COONa}\right)$, ferric chloride hexahydrate $\left(\mathrm{FeCl}_{3} .6 \mathrm{H}_{2} \mathrm{O}\right)$, Folin-Ciocalteu reagent, Dragendorff's reagent, mercuric chloride, potassium iodide, apigenin and iodine were purchased from Sigma-Aldrich Chemie $\mathrm{GmbH}$, Steinheim, Germany. Ethanol $\left(\mathrm{C}_{2} \mathrm{H}_{5} \mathrm{OH}\right)$, methanol $\left(\mathrm{CH}_{3} \mathrm{OH}\right)$, dichloromethane, hydrochloric acid $(\mathrm{HCl})$, sulfuric acid $\left(\mathrm{H}_{2} \mathrm{SO}_{4}\right)$, chloroform $\left(\mathrm{CHCl}_{3}\right)$, ammonia $\left(\mathrm{NH}_{3}\right)$, glacial acetic acid, sodium hydroxide $(\mathrm{NaOH})$, acetonitrile, acetic acid, orthophosphoric acid and potassium peroxodisulfate were bought from Merck Chemicals GmbH, Darmstadt, Germany. The chemicals used were of good quantity and quality standard and do not require further purification.

\section{Extraction}

Dried M. gigantea leaves $(10 \mathrm{~kg})$ were grinded and extracted three times with $12.5 \mathrm{~L}$ of ethanol, ( $24 \mathrm{~h}$ each) by maceration technique. The macerate was then concentrated, evaporated and dried in a vacuum at $60^{\circ} \mathrm{C}$ using a rotary evaporator (buchi rotavapor R-205). The yield value was as much as $14.8 \%(\mathrm{w} / \mathrm{w})$. The dry extract was stored in refrigerator at $4^{\circ} \mathrm{C}$ until when it will be used.

\section{Phytochemical screening}

Phytochemical screenings of the extract and isolate were perfomed to estimate the presence of its chemical constituents such as alkaloid, flavonoid, saponin, triterpenoid, steroid, tanins, glycosides and phenolic.

\section{Preparation of polymeric microparticles}

The solvent evaporation method based on the formation of $\mathrm{O} / \mathrm{W}$ emulsion was used to prepare microparticles. For the O/W method, ethyl cellulose (Ethocel $10 \mathrm{cP})(10 \%, 15 \%, 20 \%)$ or Eudragit E100 (10\%,15\%, $20 \%$ ) were dissolved in dichloromethane. $5 \mathrm{~g} M$. gigantea leaves extract were dissolved within this organic phase. The organic phase was then emulsified into $800 \mathrm{ml}$ aqueous PVA solution $(0.25 \% \mathrm{w} / \mathrm{v})$ containing $0.5 \mathrm{M} \mathrm{NaCl}$ and $\mathrm{NaOH}$ at $\mathrm{pH} 12$. The emulsion was stirred for $4 \mathrm{~h}$ at $500 \mathrm{rpm}$ with a propeller stirrer (Heidolph Elektro GmbH \& Co. KG, Kelheim, Germany) to allow microparticle hardening. After $4 \mathrm{~h}$, the microparticles were separated from the external aqueous phase by wet sieving followed by washing with $200 \mathrm{ml}$ deionized water, desiccatordrying for $24 \mathrm{~h}$ and storage in a desiccator.

\section{Particle size analysis}

Particle size mean and size distribution of the microparticles were measured by Dynamic Light scattering (DLS) (Cilas, 1064 L, France). The appropriate amount of dry microcapsules of each formulation is suspended in deionized water and sonicated for the appropriate time period before measurement. The average diameter of the volume, size distribution and polydispersite of the resulting homogeneous suspension were determined using the DLS technique. The microparticles suspension was dispersed in distilled water and then it was put into the sample chamber of particle size analyzer and measurement of vesicular size was carried out.

\section{Thin layer chromatography (TLC)}

Qualitative analysis by thin layer chromatography (TLC) on ethanol extract of $M$. gigantea leaves, and microcapsule with formula $15 \%$ Eudragit E100 polymer (FA3) and formula 15\% ethocel $10 \mathrm{cP}$ (FB3) were carried out several times using several eluents with different levels of polarity to obtain a solvent that was able to provide good separation. Spots on the TLC plate were monitored at wavelength $254 \mathrm{~nm}$ and 366 $\mathrm{nm}$. Determination of the class of compounds in the TLC test was done by spraying the TLC plate with several reagents using $10 \% \mathrm{H}_{2} \mathrm{SO}_{4}$ in methanol p.a. 


\section{Scanning electron microscopy}

The morphology of microparticles was analysed by scanning electron microscopy (SEM). For surface imaging, the microparticles were fixed on a sample holder with double-sided tape. To investigate the inner structure, the particles were spread on transparent tape and then cut with a razor blade. All samples were coated under argon atmosphere with gold to a thickness of $8 \mathrm{~nm}$ in a high-vacuum (SCD 040, Bal$\mathrm{Tec} \mathrm{GmbH}$, Witten, Germany). Samples were then analysed on the scanning electron microscope (S-4000, Hitachi High-Technologies Europe GmbH, Krefeld, Germany).

\section{Entrapment efficiency}

Microparticles $(10 \mathrm{mg}$ ) were extracted in $1 \mathrm{ml}$ methanol, followed by agitation in a horizontal shaker (IKA HS 501 digital horizontal Shaker, Janke \& Kunkel GmbH \& Co. KG IKA Labortechnik, Staufen, Germany) for $2 \mathrm{~h}(\mathrm{n}=3) .0 .1 \mathrm{ml}$ of methanol extract was diluted in 10 $\mathrm{ml}$ of $\mathrm{pH} 7.4$ phosphate buffer. The polymer was separated from aqueous solution by filtration using filter paper (Whatman;, GE Healthcare UK Limited, Buckinghamshire, UK). Flavonoid concentration in the obtained aqueous solution was determined by UV-spectrophotometry at wavelengths of $435 \mathrm{~nm}$ (HP $8453 \mathrm{UV}$-Vis spectrophotometer, Agilent Technologies Deutschland GmbH, Waldbronn, Germany). The actual drug loading and encapsulation efficiency were calculated as follows:

Encapsulation efficiency $(\%)=($ actual drug loading/theoretical drug loading) x $100 \%$

\section{Antioxidant activity}

The free radical scavenging activity of the formulation were measured by 1,1-Diphenyl-2-picrylhydrazyl (DPPH) method. Different concentrations of formulations were added to equal volume to methanolic solution of DPPH $(100 \mu \mathrm{M})$. After $15 \mathrm{~min}$ at room temperature, the absorbance was recorded at $517 \mathrm{~nm}$. The mixture was shaken vigorously and allowed to stand at room temperature for 30 minute then the absorbance was measured at $517 \mathrm{~nm}$ by using spectrophotometer. Vitamin C was used as standard compound. The percent DPPH scavenging effect was calculated using the following equation:

\section{(\%) Inhibition $=100[(\mathrm{~A} 0-\mathrm{A} 1) / \mathrm{A} 0]$}

Where, A0 was the absorbance of the control reaction and A1 was the absorbance in presence of the standard sample.

\section{RESULT AND DISCUSSION}

The phytochemical screening of crude ethanolic extract of $M$. gigantea leaf revealed the presence of some secondary metabolites such as alkaloids, steroids, flavonoids, phenolics and tanins (Table 1). These phytochemical compounds are known to be responsible for some medicinal activity which in this present study is antioxidant activity.

\section{Microparticle}

Preparation of microparticles by solvent evaporation is widely used in pharmaceutical industry. It can be applied for encapsulation of a broad

Table 1: Phytochemical screening of ethanolic leaf extract of Macaranga gigantea.

\begin{tabular}{cc}
\hline Secondary metabolites & Results \\
\hline Alkaloids & + \\
Flavonoids & + \\
Tanins & + \\
Phenolic & + \\
Steroids & + \\
Terpenoids & - \\
Saponins & - \\
Glycosides & - \\
\hline
\end{tabular}

range of substances, from simple drugs to proteins and DNA. ${ }^{23,24}$ There are several variation of the solvent evaporation technique that have been developed to get efficient drug encapsulation for hydrophilic and hydrophobic drugs. For insoluble or poorly water-soluble drugs, the oil-in-water $(\mathrm{O} / \mathrm{W})$ method is frequently used. While for water soluble drugs, the water-in-oil-in-water $(\mathrm{W} / \mathrm{O} / \mathrm{W})$ method is preferred. ${ }^{34}$

In case of the preparation of polymeric microparticles for sustained drug release by solvent evaporation technique, the solidification rate is a decisive factor for their release behaviour. A very slow hardening of the emulsion droplets leads to the diffusion of the drug substance out of the droplets and encapsulation efficiency becomes low. Solidification rate of polymeric microparticles during solvent evaporation process influenced solubility of polymers in organic solvents and solubility organic solvent in water, which in turn affects microparticle properties such as particle size, drug incorporation, matrix porosity, solvent residues and initial burst. ${ }^{30-37}$ Various types of solvent with different physical properties (such as miscibility or solubility, volatility, boiling point, reactivity, viscosity, etc.) have been used to prepare polymeric microparticles. Dichloromethane is the most common solvent for the encapsulation using solvent evaporation technique because of its high volatility, low boiling point and high immiscibility with water. ${ }^{23,34,37}$

Microencapsulation techniques with film polymers can use several typesof polymers including Eudragit E100 and Ethocel $10 \mathrm{cP}$. Eudragit E100 is a cationic polymer based on dimethylaminoethyl methacrylate, butyl methacrylate, and methyl methacrylate. Eudragit E100 dissolves in gastric fluid and also in weak acid buffer solutions, up to $\mathrm{pH} \sim 5$. The glass transition temperature of Eudragit E100 is $\sim 48^{\circ} \mathrm{C}$. If it used as a polymer cover in microencapsulation, eudragit E100 forms a film that is easily soluble, permeable, and insoluble at $\mathrm{pH} 5$ or higher, but dissolves rapidly by forming salts at acidic $\mathrm{pH}$, lower than 5 . This polymer can prevent the release of drugs in saliva at $\mathrm{pH} 6.8-7.4$, on the other hand it will dissolve directly in stomach fluid at $\mathrm{pH} 1.0-1.5{ }^{26-29}$

Ethyl cellulose (EC) is a partly O-ethylated cellulose ether derivative. It is available in a variety of grades, which differ in viscosity, usually hydrophobic in nature and widely used in the biomedical and pharmaceutical industries. Ethyl cellulose is usually distinguished by viscosity, molecular weight, and is referred to as "Ethyl Cellulose Polymer Premium", with the trade name Ethocel TM. Ethocel TM types are ethocel $4,7,10,20,45$ and $100 \mathrm{cP}$. The one used in this research is ethocel $10 \mathrm{cP}$ because it is most used in coating many purposes such as odour and taste masking, protection, and controlled release of drugs..$^{29,31}$

Ethanol extract of $M$. gigantea leaves has low stability because it contains natural ingredients. Formulation of extract into microcapsules by using polymer is purposed to protect the extract as an active ingredient. The polymer used were eudragit E100 and ethocel $10 \mathrm{cP}$ at concentration of 5,10 and $15 \%$. PVA in microcapsule prepared by solvent evaporation method is commonly used as a polymer stabilizing agent. PVA has water-soluble properties, slightly soluble in ethanol (95\%) besides PVA has a characteristic odor with white granules. However, the use of the polymer must be able to guarantee the stability of the extract, especially in terms of activity.

Based on observations of microcapsules from ethanol extract of $M$. gigantea leaves using type and concentration of polymer variations, it is obtained that yields of each formulation were $5.024 \mathrm{~g}$ for $5 \%$ eudragit E100; $5.072 \mathrm{~g}$ for 10\% eudragit E100 ; and $5.082 \mathrm{~g}$ for eudragit 15\% E100. Using Ethocel $10 \mathrm{cP}$ as polymer, the yields values were $5.275 \mathrm{~g}$ for $5 \%$ ethocel $10 \mathrm{cP} ; 5.744 \mathrm{~g}$ for $10 \%$ ethocel $10 \mathrm{cP}$; and $5.818 \mathrm{~g}$ for $15 \%$ ethocel $10 \mathrm{cP}$ (Table 2). It can be concluded that the higher the concentration used in formulation, the higher the yield obtained.

Based on the results of the particle size characterization of $M$. gigantea leaf extract microcapsules, by using 5\% Eudragit E100 the particle size was $3.564 \mu \mathrm{m}$; when $10 \%$ eudragit E100 polymer was used, particle size 
was $3.998 \mu \mathrm{m}$; while 15\% Eudragit E100 was used, the particle size was $4.514 \mu \mathrm{m}$. The analysis data shows that the particle size is categorized into a micro size (above $1 \mu \mathrm{m}$ ). Formula that used $5 \%$ ethocel $10 \mathrm{cP}$ polymer produced a particle size of $3.928 \mu \mathrm{m}$. The formula that uses $10 \%$ ethocel $10 \mathrm{cP}$ polymer produces a particle size of $4.469 \mu \mathrm{m}$. Whereas the formula using $15 \%$ ethocel $10 \mathrm{cP}$ produces a particle size of $5.887 \mu \mathrm{m}$. From 3 variations of Eudragit E100 and Ethocel $10 \mathrm{cP}$ polymers, it can be seen that at $15 \%$ concentration of polymer, largest particle size of microcapsules was the highest compared to that with $5 \%$ and $10 \%$ (Table 2). But these particle size is still categorized into a micro size (above $1 \mu \mathrm{m}$ ).

Calculation on the \% encapsulation efficiency (\% EE) aimed to find out on how much \% of the ethanol extract of $M$. gigantea leaves can be coated by polymer. In the formula using $5 \%$ eudragit E100 polymer, the EE value was $72.746 \%$. By using $10 \%$ eudragit E100 polymer, the \% EE value was $84.114 \%$, while by using $15 \%$ eudragit E100, the $\%$ EE value was become $85.978 \%$. The process can be categorized as good because it has the $\% \mathrm{EE}$ value of $\geq 80 \%$. Microcapsule formula of $M$. gigantea extract that use $5 \%$ ethocel $10 \mathrm{cP}$ polymer revealed the $\% \mathrm{EE}$ value as much as $77.995 \%$. The formula with $10 \%$ ethocel $10 \mathrm{cP}$ polymer gave the $\% \mathrm{EE}$ value of $86.784 \%$, while that with $15 \%$ ethocel $10 \mathrm{cP}$ polymer gave the $\% \mathrm{EE}$ value of $88.992 \%$. It can be concluded that by using concentration $5-15 \%$ of ethocel $10 \mathrm{cP}$ polymer, the value of $\% \mathrm{EE}$ was categorized as good (Table 2).

\section{Zeta potential}

Zeta Potential Analysis is a technique for determining the surface charge of particles in a solution (colloid). Microparticles have a surface charge that attracts a thin layer of charge ions that is opposite to the surface of the microparticles. The double ion layer together with the microparticles diffuses throughout the solution. The electrical potential at the bilayer boundary is known as the Zeta potential of the particle and has values that typically range from $100 \mathrm{mV}$ to $-100 \mathrm{mV}$. The magnitude of the zeta potential can predict colloidal stability. Microparticles with a Zeta Potential value greater than $+25 \mathrm{mV}$ or less than $-25 \mathrm{mV}$ usually have a high degree of stability. Dispersions with low zeta potential value will produce aggregates due to inter-particle Van Der Waals attractions.

Zeta potential value of $M$. gigantea leaves ethanol extract microcapsule $(\mathrm{FA3}=$ Eudragit E100 Formula $(15 \%))$ that values $-15.6 \mathrm{mV}$, while that microcapsule containing M. gigantea leaves $(\mathrm{FB} 3=$ Ethocel 10 cP Formula (15\%)) was $-10.2 \mathrm{mV}$ (Figure 1). It showed that the two polymers used in preparation of microcapsules produce dispersions with low zeta potential values that will produce aggregates due to interparticle Van Der Waals attractions.

\section{Thin layer chromatography}

Thin layer chromatography (TLC) is a method of separating components of chemical compounds based on the principle of adsorption and partitioning which is determined by the mobile phase (eluent) and the stationary phase (adsorbent). The use of the TLC method is intended as an initial qualitative analysis of the stability of the active ingredients used. Components of chemical compounds move up to follow the mobile phase because the adsorbent absorption of chemical components is not the same so that chemical components can move at different distances based on the level of polarity. This is what causes the separation of components of chemical compounds in the extract.

The results obtained from the ethanol extract of $M$. gigantea leaves seen at $366 \mathrm{~nm}$ showed the presence of four and five spot with varying Rf values (Figure 2 and Table 3).

Table 2: Data of microcapsules of $M$. gigantea leaves ethanol extract followed by stirring by propeller stirrer 500 rpm (4 hours).

\begin{tabular}{|c|c|c|c|c|c|}
\hline Formula & \multicolumn{2}{|c|}{ Material } & Product (g) & PSA $(\mu \mathrm{m})$ & $\mathrm{EE}(\%)$ \\
\hline \multirow{3}{*}{$\mathrm{FA}_{1}$} & Extract & $=5 \mathrm{~g}$ & & & \\
\hline & Eugragit & $0=5 \%$ & 5.024 & 3.564 & 72.746 \\
\hline & PVA & $=1.5 \%$ & & & \\
\hline \multirow{3}{*}{$\mathrm{FA}_{2}$} & Extract & $=5 \mathrm{~g}$ & & & \\
\hline & Eugragit & $0=10 \%$ & 5.072 & 3.998 & 84.114 \\
\hline & PVA & $=1.5 \%$ & & & \\
\hline \multirow{3}{*}{$\mathrm{FA}_{3}$} & Extract & $=5 \mathrm{~g}$ & & & \\
\hline & Eugragit & $0=15 \%$ & 5.082 & 4.514 & 85.978 \\
\hline & PVA & $=1.5 \%$ & & & \\
\hline \multirow{3}{*}{$\mathrm{FB}_{1}$} & Extract & $=5 \mathrm{~g}$ & & & \\
\hline & Ethocel & $P=5 \%$ & 5.275 & 3.928 & 77.995 \\
\hline & PVA & $=1.5 \%$ & & & \\
\hline \multirow{3}{*}{$\mathrm{FB}_{2}$} & Extract & $=5 \mathrm{~g}$ & & & \\
\hline & Ethocel & $=10 \%$ & 5.744 & 4.469 & 86.784 \\
\hline & PVA & $=1.5 \%$ & & & \\
\hline \multirow{3}{*}{$\mathrm{FB}_{3}$} & Extract & $=5 \mathrm{~g}$ & & & \\
\hline & Ethocel & $P=15 \%$ & 5.818 & 5.887 & 88.992 \\
\hline & PVA & $=1.5 \%$ & & & \\
\hline
\end{tabular}

Annotation :

$\mathrm{FA}_{1}=$ Formula with eudragit E100 (5\%)

$\mathrm{FA}_{2}=$ Formula with eudragit $\mathrm{E} 100(10 \%)$

$\mathrm{FA}_{3}=$ Formula with eudragit E100 (15\%)

$\mathrm{FA}_{1}=$ Formula with ethocel $10 \mathrm{cP}(5 \%)$

$\mathrm{FA}_{2}=$ Formula with ethocel $10 \mathrm{cP}(10 \%)$

$\mathrm{FA}_{3}=$ Formula with ethocel $10 \mathrm{cP}(15 \%)$

PVA = Polivinyl Alkohol

PSA $=$ Particle Size Analyzer

$\mathrm{EE}=$ Encapculation efficiency 


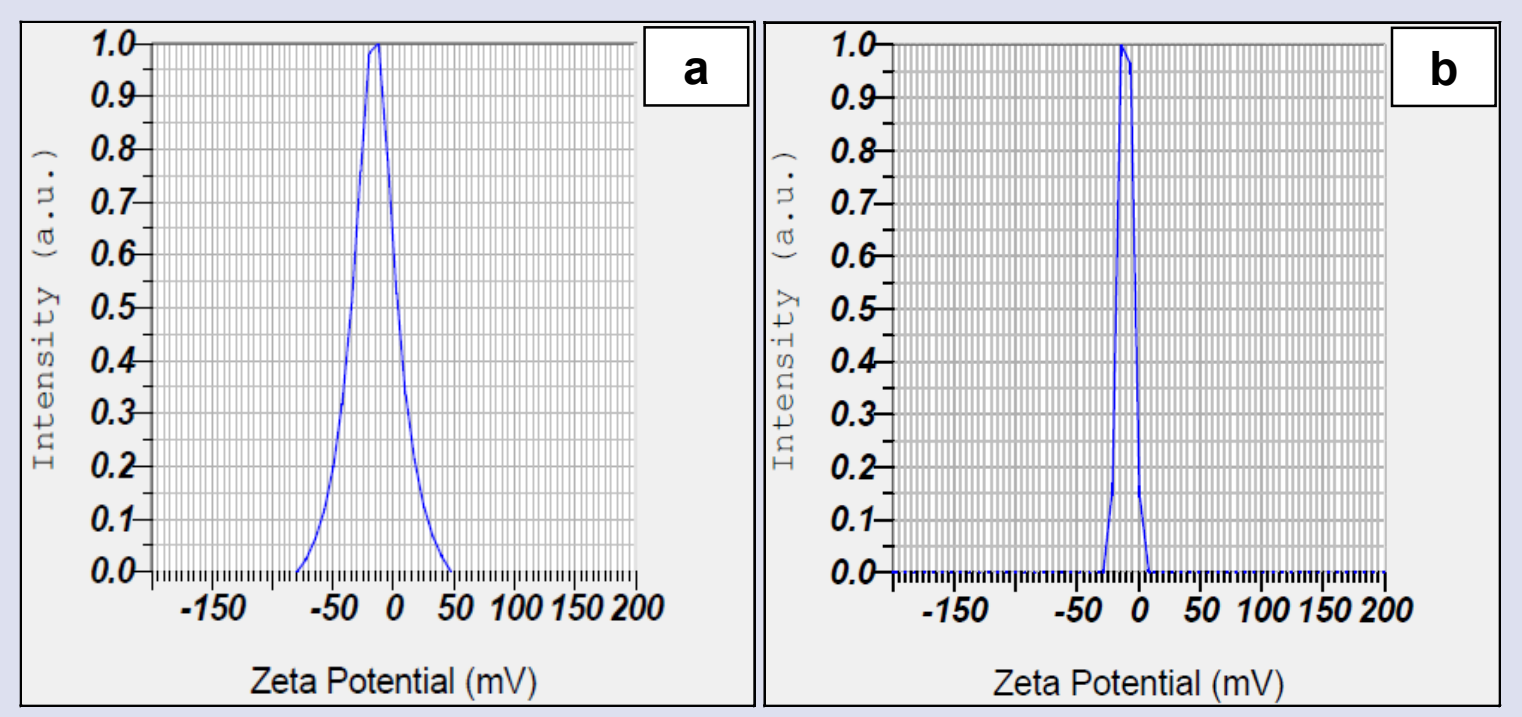

Figure 1: Zeta potential profile of M. gigantea leaves ethanol extract microcapsule, (a) FA ${ }_{3}=$ Eudragit E100 Formula (15\%); (b) FB $3=$ Ethocel 10 cP Formula (15\%).

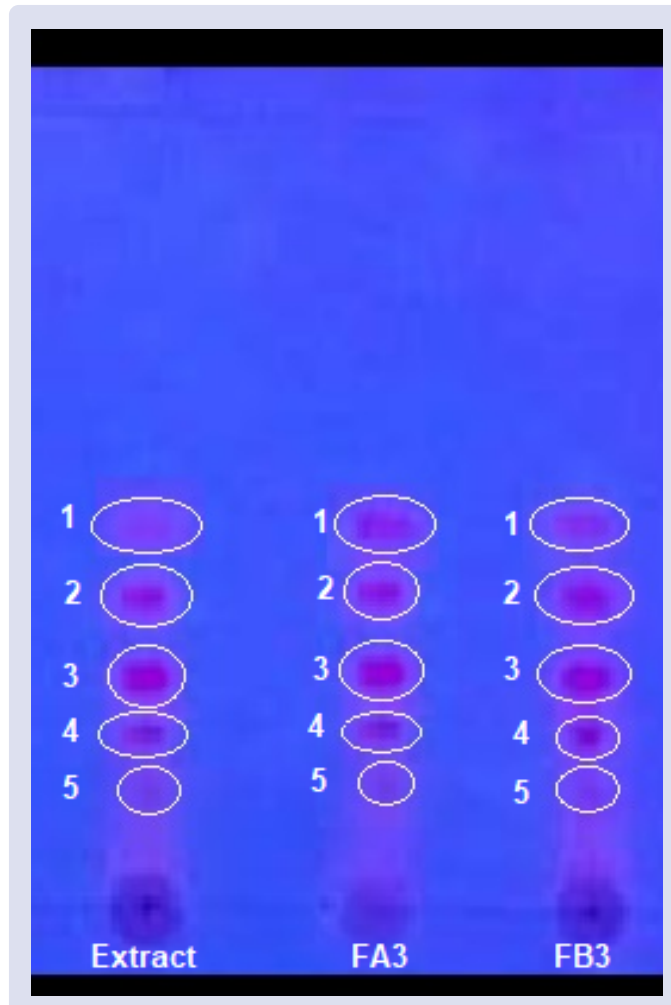

Figure 2: TLC profile of $M$. gigantea leaves ethanol extract; FA3 = Eudragit E100 Formula (15\%); FB3 = Ethocel Formula $10 \mathrm{cP}(15 \%)$ under UV light $366 \mathrm{~nm}$.

Table 3: Rf value in thin layer chromatography profiles.

\begin{tabular}{cccc}
\hline Rf Value & Extract & FA3 & FB3 \\
\hline 1 & 0.59 & 0.6 & 0.49 \\
2 & 0.49 & 0.5 & 0.51 \\
3 & 0.34 & 0.35 & 0.35 \\
4 & 0.26 & 0.27 & 0.25 \\
5 & 0.15 & 0.18 & 0.17 \\
\hline
\end{tabular}


It can be seen from the results of TLC (Figure 2), the presence of polymers as excipient in microencapsulation process did not affect the stability of compounds in the ethanol extract of $M$. gigantea leaves. So it can be concluded that there were no incompatibility between the extract and polymer (E100 Eudragit polymer (FA3) and ethocel $10 \mathrm{cP}$ (FB3)) after they were formulated into microcapsules.

\section{Scanning electron microscope}

Microcapsules refer to particles with a diameter of 1-1000 $\mu \mathrm{m}$. Microcapsules are usually described as a mixture consist of active substances and polymers. Based on the results of particle size and \% EE evaluations, formula using $15 \%$ eudragit E100 polymer $\left(\mathrm{FA}_{3}\right)$ and the formula using $15 \%$ ethocel $10 \mathrm{cP}$ polymer $\left(\mathrm{FB}_{3}\right)$ were assumed as best formulation. Therefore, the two formula were subjected to next characterization which was SEM picture analysis.

Results of Scanning electron microscopy revealed that microcapsules using Eudragit E100 polymers have a rough and porous surface (Figure 3. a1 and a2) while ethocel $10 \mathrm{cP}$ has a smoother surface and less visible pores (Figure 3. b1 and b2). The microcapsules using eudragit E100 polymer have a particle size of $4.514 \mu \mathrm{m}$ while those using ethocel $10 \mathrm{cP}$ polymer have a particle size of $5.882 \mu \mathrm{m}$. The resulting particle size has met the size requirements of the microcapsules.

\section{Antioxidant activity}

The antioxidant reacts with stable free radical, DPPH and converts it to 1,1-Diphenyl-2- Picryl Hydrazine. The ability to scavenge the free radical, DPPH was measured at an absorbance of $517 \mathrm{~nm}$. So the DPPH -RSA and its \%inhibition of ethanol extracts of $M$. gigantea leaves that $\mathrm{IC}_{50}$ values $63.75 \mathrm{ppm}$ and microcapsule showed that $\mathrm{IC}_{50}$ values $64.51 \mathrm{ppm}$ (Table 4). Ascorbic acid (Vitamin C) has taken as reference which showed $7.24 \mathrm{ppm}$ (Table 4). The Results showed that both ethanolic extracts of $M$. gigantea and microcapsule containing extracts of $M$. gigantea leaves have potent antioxidant activity. According to Molyneux (2004), parameters for antioxidant testing based on the ability to inhibit free radicals $50 \%$ are categorized if $<50$ (Very Strong), 50-100 (Strong), 101-150 (Medium), > 150 (Weak). The ability of vitamin $\mathrm{C}$ can inhibit free radical activity and is classified as very strong $\left(\mathrm{IC}_{50}<50 \mathrm{ppm}\right)$, due to more hydroxyl groups in its structure, so it can stabilize free radicals. Antioxidant ability of ethanol extracts of $M$. gigantea leaves expressed as $\mathrm{IC}_{50}$ values was $63.75 \mathrm{ppm}$, while that after formulated into microcapsule showas $64.51 \mathrm{ppm}$. The results showed that microencapsulation process did not affect the antioxidant activity of the extract. This activity may due to many compounds either as extract or microcapsule that are possible as a source of free radical stabilizing hydroxyl groups. Antioxidant activity is influenced by the number of hydroxyl groups that are able to donate hydrogen atoms to neutralize free radicals. The results was supported by TLC profile of extract and microcapsules which remained stable and revealed the same spots. This means that formulation process and addition of the coating polymer do not affect the pharmacological stability of extract.

The antioxidant activity of the extract is due to secondary metabolite content. In phytochemical screening, extracts have secondary metabolites, namely alkaloids, flavonoids, tannins, phenolic and steroids. These compounds are responsible for the antioxidant activity.

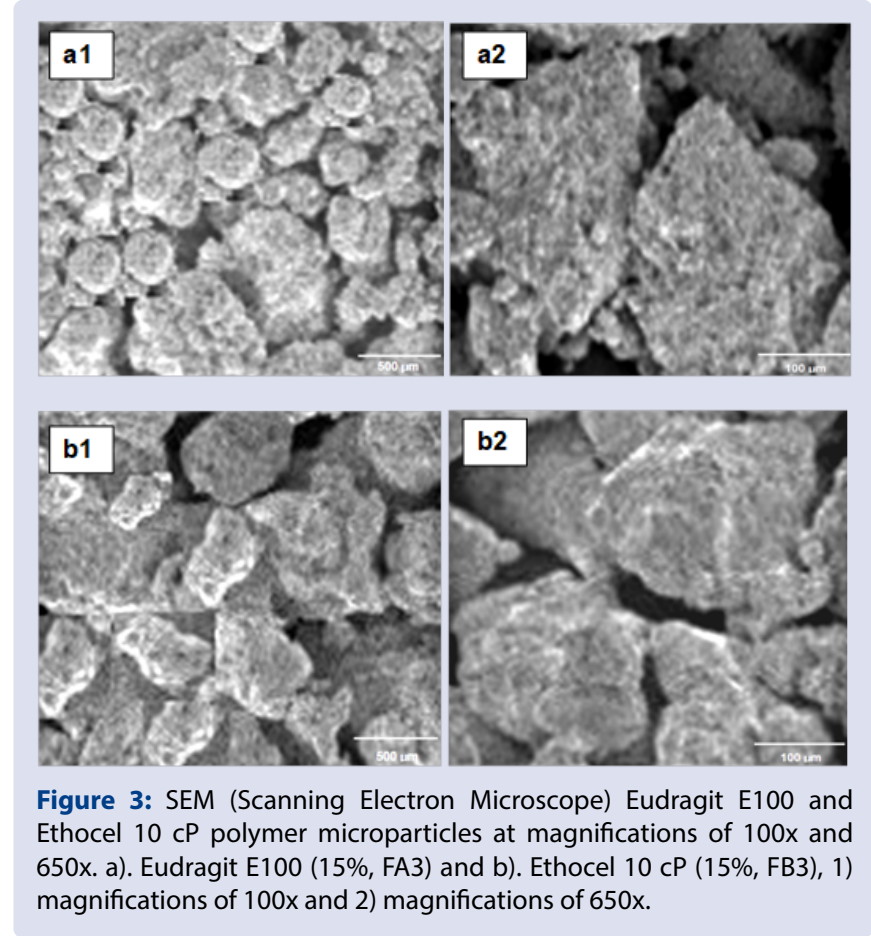

Table 4: Antioxidant Activity of microcapsules of $M$. gigantea ethanol leaves extract.

\begin{tabular}{|c|c|c|c|c|}
\hline No. & Sample & Equation & $\mathrm{R}^{2}$ Value & $I C_{50}$ Value \\
\hline 1 & Ascorbic Acid (Vitamin C) & $y=9.526 x-17.234$ & 0.987 & $7.24 \mathrm{ppm}$ \\
\hline 2 & $\begin{array}{c}\text { Ethanol extracts of } M \text {. gigantea } \\
\text { leaves }\end{array}$ & $y=0.895 x-7.782$ & 0.944 & $63.75 \mathrm{ppm}$ \\
\hline 3 & $\begin{array}{c}\text { Microcapsule } \\
\text { (contain ethanol extracts of } M . \\
\text { gigantea leaves) }\end{array}$ & $y=0.897 x-7.648$ & 0.937 & $64.51 \mathrm{ppm}$ \\
\hline
\end{tabular}




\section{CONCLUSION}

Based on the results of the data, it can be concluded that microcapsules of $M$. gigantea leaves extract can be prepared by solvent evaporation method $(\mathrm{O} / \mathrm{W}$ : oil in water) by using Eudragit E100 and Ethocel $10 \mathrm{cP}$ as polymer. Characterization of the microcapsules revealed that parameter process used on this method is applicable to produce microcapsules which stable in physical properties and also in pharmacological activity as antioxidant.

\section{ACKNOWLEDGEMENT}

The authors gratitude the Directorate General of Higher Education; the Ministry of Education and Culture and the Ministry of Research and Technology, Republic of Indonesia for their support on this project under the Excellent Research of University Grant year 2020.

\section{CONFLICTS OF INTEREST}

No conflicts of interest is associated with this work.

\section{REFERENCES}

1. Sansone $F$, Mencherini $T$, Picerno $P$, Amore $M$, Aquino RP, Lauro MR. Maltodextrin/pectin microparticles by spray drying as carrier for nutraceutical extracts. J Food Eng. 2011;105:468-76.

2. Poomkokrak J, Niamnuy C, Choicharoen K, Devahastin S. Encapsulation of soybean extract using spray drying. J Food Sci Agric Technol. 2015;1:105-10.

3. Manganaris GA, Goulas V, Vicente R, Terry LA. Berry antioxidants: Small fruits providing large benefits. Sci Food Agric. 2014;94:825-33.

4. Rajbhar K, Dawda H, Mukundan U. Polyphenols: Methods of extraction. Sci Revs Chem Commun. 2015;5:1-6.

5. Zhou D, Zhou F, Ma J, Ge F. Microencapsulation of Ganoderma lucidum spores oil: Evaluation of its fatty acids composition and enhancement of oxidative stability. Ind Crop Prod. 2019;131:1-7.

6. Tolun A, Altintas Z, Artik N. Microencapsulation of grape polyphenols using maltodextrin and gum Arabic as two alternative coating materials: Development and characterization. J Biotechnol. 2016;239:23-33.

7. Muhaimin M, Yusnaidar $Y$, Syahri W, Latief $M$, Putri RD, Utami A, et al. Antiplasmodial Activity of Ethanolic Extract of Macaranga Ggigantea Leaf and Its Major Constituent. Pharmacog J. 2019;11(6):1181-8.

8. Mazlan NA, Mediani A, Abas F, Ahmad S, Shaari K, Khamis S, et al. Antioxidant, antityrosinase, anticholinesterase and nitric oxide inhibition activities of three Malaysian Macaranga species. The Sci World J. 2013;1:1-7.

9. Magadula JJ. Phytochemistry and pharmacology of the genus Macaranga: A review. J Med Plant Res. 2014;8(12):489-503.

10. Muhaimin, Syamsurizal, Chaerunisaa AY, Sinaga MS. Eusiderin I from Eusideroxylon zwagery as antifungal agent against plant pathogenic fungus. Int J ChemTech Res. 2016;9(5):418-24.

11. Aminah NS, Kristanti AN, Tanjung M. Antioxidant activity of flavonoid compounds from the leaves of Macaranga gigantea. J Chem Pharm Res. 2014;6(6):688-92.

12. Lim TY, Lim YY, Yule CM. Evaluation of antioxidant, antibacterial and antityrosinase activities of four Macaranga species. Food Chem. 2009;114:5948.

13. Ngoumfo RM, Ngounou GE, Tchamadeu CV, Qadir MI, Mbazoa CD, Begum $A$, et al. Inhibitory Effect of Macabarterin, a polyoxygenated Ellagittannin from Macaranga barteri, on human neutrophil respiratory burst activity. Phytochem. 2008;61:867-72.

14. Yoder BJ, Cao S, Norris A, Miller JS, Ratovoson F, Razafitsalama J, et al. Antiproliferative Prenylated Stilbenes and Flavonoids from Macaranga alnifolia from the Madagascar Rainforest. J Nat Prod. 2007;70:342-6.
15. Zakaria I, Ahmat N, Jaafar FM, Widyawaruyanti A. Flavonoids with antiplasmodial and cytotoxic activities of Macaranga triloba. Fitotera. 2012;83:968-72.

16. Matsunami K, Otsuka H, Kondo K, Shinzato T, Kawahata M, Yamaguchi K, et al Absolute configuration of (+)-pinoresinol 4-O-[6"-O-galloyl]- $\beta$-Dglucopyranoside, macarangiosides $\mathrm{E}$ and $\mathrm{F}$ isolated from the leaves of Macaranga tanarius. Phytochem. 2009;70:1277-85.

17. Schutz BA, Wright $A D$, Rali T, Sticher O. Prenylated flavanones from the leaves of Macaranga pleiostemona. Phytochem. 1995;40:1273-7.

18. Jang DS, Cuendet M, Hawthorne ME, Kardono LBS, Kawanishi K, Fong HHS, et al. Prenylated flavonoids of the leaves of Macaranga conifera with inhibitory activity against cyclooxygenase-2. Phytochem. 2002;61:867-72.

19. Thanh VTT, Mai HDT, Pham VC, Litaudon M. Acetylcholinesterase inhibitors from leaves of Macaranga kurzii. J Nat Prod. 2012;75:2012-5.

20. Muhaimin M, Latief M, Putri RD, Chaerunisaa AY, Aditama AY, Pravitasari NE, et al. Antiplasmodial Activity of Methanolic Leaf Extract of Mangrove Plants against Plasmodium berghei. Pharmacog J. 2019;11(5):929-35.

21. Muhaimin, Yusnaidar, Syahri W, Latief $M$, Utami $A$, Bemis $R$, et al. Screening and potential analysis of methanolic leaf extract of Mangrove plants at east coast Sumatera as repellent against Aedes aegypti. J Pharm Sci Res. 2018;10(9):2228-31.

22. Martins IM, Barreiro MF, Coelho M, Rodrigues AE. Microencapsulation of essential oils with biodegradable polymeric carriers for cosmetic applications. Chem Eng J. 2014; 245:191-200.

23. Muhaimin, Bodmeier R. Effect of solvent type on preparation of ethyl cellulose microparticles by solvent evaporation method with double emulsion system using focused beam reflectance measurement. Polymer Int. 2017;66(11):144855.

24. Dias DR, Botrel DA, Victoria R, Fernandes DB, Borges SV. Encapsulation as a tool for bioprocessing of functional foods. Curr Opin Food Sci. 2017;13:31-7.

25. Pai DA, Vangala VR, Ng JW, Ng WK, Tan RBH. Resistant maltodextrin as a shell material for encapsulation of naringin: Production and physicochemical characterization. J Food Eng. 2015;161:68-74.

26. Seethadevi SJSRI, Prabha A, Muthuprasanna P. Microencapsulation: A review involved. Int J Pharma Biol Sci. 2012;3:509-31.

27. Chawda PJ, Shi J, Xue S, Quek SY. Co-encapsulation of bioactives for food applications. Food Qual Saf. 2017;1:302-9.

28. Muhaimin M, Syamsurizal $S$, Latief $M$, Iskandar $R$, Chaerunisaa AY, Mujahidin D, Synthesis of 7,3'-Epoxy-8,4'-Oxyneolignane-1'-Carboxylic Acid from Natural Eusiderin A and its Activity Against Trichophyton mentagrophytes, Curr Organocat. 2020;7:44-54.

29. Hoyos-leyva JD, Bello-pérez LA, Hugo S. Microencapsulation using starch as wall material: A review. Food Rev Int. 2018;34:148-61.

30. Borghetti GS, Lula IS, Sinisterra RD, Bassani VL. Quercetin/beta-cyclodextrin solid complexes prepared in aqueous solution followed by spray-drying or by physical mixture. AAPS Pharm Sci Tech. 2009;10:235-42.

31. Alhnan MA, Basit AW. Engineering polymer blend microparticles: An investigation into the influence of polymer blend distribution and interaction. Eur J Pharm Sci. 2011;42:30-6.

32. Doulabia AH, Mirzadeha H, Imanib M, Samadic N. Chitosan/polyethylene glyco fumarate blend film: Physical and antibacterial properties. Carbohyd Polym. 2013;92:48-56

33. Duarte ARC, Gordillo MD, Cardoso MM, Simplicio AL, Duarte CMM. Preparation of ethyl cellulose/methyl cellulose blends by supercritical antisolvent precipitation. Int J Pharm. 2006;311:50-4.

34. Freitas S, Merkle HP, Gander B. Microencapsulation by solvent extraction/ evaporation: reviewing the state of the art of microsphere preparation process technology. J Control Rel. 2005;102:313-32.

35. Murtaza G. Ethylcellulose microparticles: A review. Drug Res. 2012;69:11-22.

36. Chaerunisaa AY, Muhaimin. Comparative study on release of two drugs in fixed dose combination using zeroorder and first derivative spectrophotometry. Int J PharmTech Res. 2016;9(12):581-90.

37. Muhaimin M, Bodmeier R. Data on the application of the focused beam reflectance measurement (FBRM): A process parameters dataset for the ethyl cellulose $(E C)$ microparticles preparation by the solvent evaporation method. Data in Brief. 2020;30:1-14. 


\section{GRAPHICAL ABSTRACT}

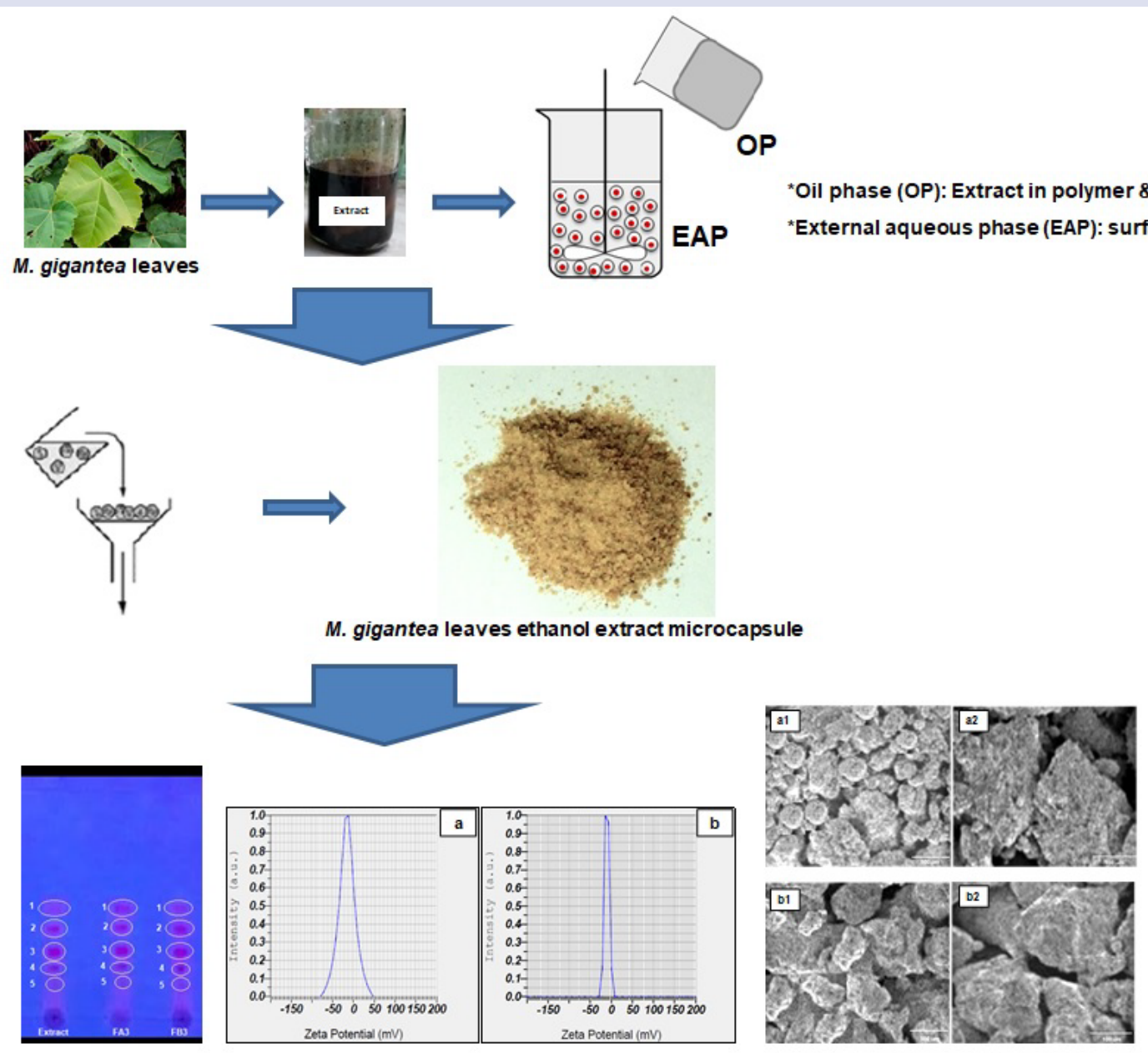

\section{ABOUT AUTHORS}
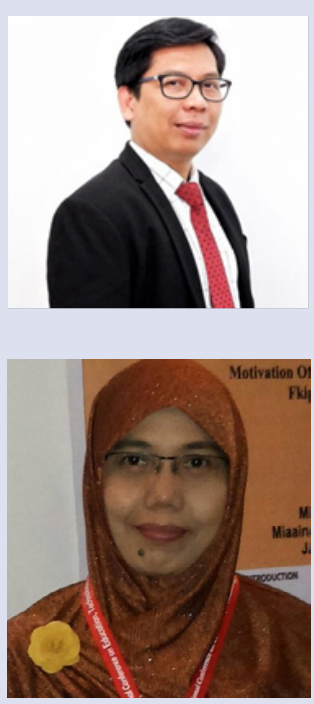

Muhaimin Muhaimin: Associate Professor at Department of Chemistry Education, Faculty of Education, University of Jambi, Jambi, Indonesia. He has experience in the area of Organic Chemistry, Pharmaceutical Technology, and Pharmacognosy, working in drug delivery, drugs discovery of herbal plants, antimalaria and infectious disease. His research also focus on polymer and organic chemistry from mechanistic studies to synthetic methodology and the synthesis of natural products as well as of structurally intriguing heterocyclic compounds. The central focus of the research is the design of new methods for the synthesis of bioactive and synthetically versatile compounds. Other his research focus on innovative drug delivery systems with controlled drug release.

Yusnaidar Yusnaidar: Lecturer and Researcher at Department of Chemistry Education, Faculty of Education, University of Jambi, Jambi, Indonesia. She has experience in the area of Polymer and Physical Chemistry. 


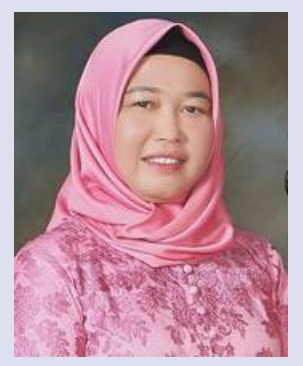

Wilda Syahri: Lecturer and Researcher at Department of Chemistry Education, Faculty of Education, University of Jambi, Jambi, Indonesia. She has experience in the area of Natural Polymer and Physical Chemistry.

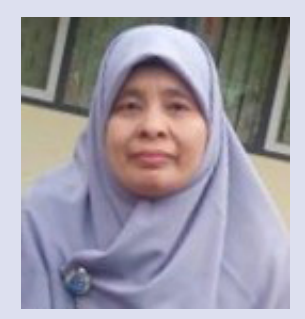

Madyawati Latief: Lecturer and Researcher at Department of Chemistry, Faculty of Science and Technology, University of Jambi, Indonesia. She has experience in the area of Natural Product and Organic Chemistry.

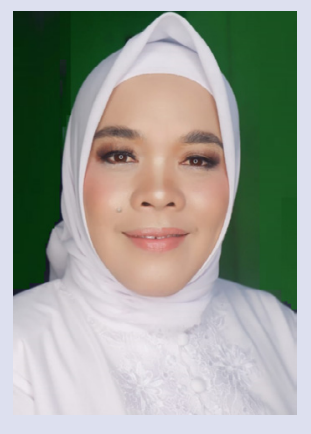

Anis Yohana Chaerunisaa: Associate Professor at Department of Pharmaceutical Technology, Faculty of Pharmacy, Padjadjaran University, Jatinangor, Indonesia. She has experience in the area of Pharmaceutical Technology and Pharmacognosy, working in drug delivery, drugs discovery of herbal plants, biodegradable polymer, and infectious disease.

Cite this article: Muhaimin M, Yusnaidar Y, Syahri W, Latief M, Chaerunisaa AY. Microencapsulation of Macaranga gigantea Leaf Extracts: Production and Characterization. Pharmacogn J. 2020;12(4):716-24. 